\title{
Temporal change in India's imbalance of carbon emissions embodied in international trade
}

Zhenyu Wanga ${ }^{\mathrm{a}}$ Jing Meng,c*, Heran Zheng ${ }^{\mathrm{d}}$, Shuai Shao ${ }^{\mathrm{a}}$, Daoping Wanga ${ }^{\mathrm{a}}$, Zhifu Mie, Dabo Guan ${ }^{\mathrm{a}, \mathrm{d}, \mathrm{f}_{*}}$

a School of Urban and Regional Science, Shanghai University of Finance and Economics, Shanghai, China.

${ }^{\mathrm{b}}$ Department of Politics and International Studies, University of Cambridge, Cambridge CB3 9DT, UK

c Cambridge Center for Environment, Energy and Natural Resource Governance, Department of Land Economy, University of Cambridge, Cambridge, CB3 9EP, UK

${ }^{\mathrm{d}}$ Water Security Research Center, School of International Development, University of East Anglia, Norwich, UK.

e The Bartlett School of Construction and Project Management, University College London, London, UK.

${ }^{\mathrm{f}}$ Department of Earth System Science, Tsinghua University, Beijing, China.

\begin{abstract}
In India, rapid industrialization and reorganization of the global supply chain are driving economic growth, accompanied by increasing exports and carbon emissions. India is poised to succeed China as the next world manufactory, which will lead to huge emissions in the country. To formulate appropriate emission mitigation measures, it is necessary to further understand the temporal change in India's emissions at the sectoral level from both the production and consumption perspectives. However, existing studies that have estimated emissions in India have paid less attention to the link among original emitters, final producers and final consumers and to its temporal change. Based on an emission inventory compiled in this study, we trace emission flows from original emitters to final producers and then to final consumers through the international supply chain by using an environmentally extended multi-regional input-output model. This study finds that both production-based and consumption-based emissions in India increased constantly from 2000 to 2014, and production-based emissions had higher growth rates due to the increased coal share. The major receivers of India's exported emissions were developed countries (e.g., the European Union and the United States), while the main sources of India's imported emissions were developing countries (e.g., China and Russia). From 2011 to 2014, India's net exported emissions increased by $29.2 \%$ because of the decrease of imported emissions. Moreover, intermediate products $(63 \%$ and $73.7 \%)$ were the major contributors to exported and imported emissions, most of which were embodied in manufacturing products ( $48.8 \%$ and $65.7 \%$, respectively). Therefore, international cooperation to optimize the energy and trade structure and to improve energy efficiency can be effective in mitigating carbon emissions in India.
\end{abstract}

\footnotetext{
*Corresponding author. Email address: jm2218@cam.ac.uk (Jing Meng), Dabo.Guan@uea.ac.uk (Dabo Guan)
} 
Keywords: India; Production-based emissions; Consumption-based emissions; Embodied emission imbalance; Total emission intensity; Multi-regional input-output analysis

\section{Introduction}

Climate change has become one of the greatest environmental challenges that humans currently face $[1,2]$. Most carbon emissions in the atmosphere were emitted by anthropogenic activities [3], and the volume of emissions increased by $39.5 \%$ from 2000 to 2015 due to the increasing consumption of fossil fuels worldwide [4]. In response, the Paris Agreement established the goal of restraining the global average temperature to within 2 degrees above preindustrial levels, and the principles of equity and common but differentiated responsibilities were applied to mitigate emissions based on the capabilities of the signers [5].

As the second largest developing economy, India has a good baseline emission intensity (Fig. 1), which decreased from $1.0 \mathrm{~kg}$ per dollar in 2000 to $0.8 \mathrm{~kg}$ per dollar in 2008 because of the country's service-oriented economy, which features low emissions and high added value [6]. However, there was a substantial increase in emission intensity in 2009 due to the low energy efficiency caused by India's economic incentive policy in manufacturing [7,8], which will consume more energy than services for each unit of economic output. India's emission intensity was higher than that of China, and the gap between these intensities increased after 2011 as a result of the increasing proportion of coal consumption in India's energy mix. In response, India's government has committed its mitigation goals in its Intended Nationally Determined Contribution, which includes reducing the carbon emissions per-unit GDP from its 2005 level by $33-35 \%$ by 2030 . This goal is less stringent than that of China (60-65\%) for the same period $[9,10]$.

These stricter environmental standards will encourage China to promote its industrial structure and to transfer its resource-intensive and labor-intensive products to countries with more relaxed environmental standards [11-13], and India will be poised to become the next world manufactory due to its loose environmental policy and low rent [14]. Emissions in China seem to have stabilized because of this reorganization of the global supply chain [15-17], and India's emissions will increase rapidly and continuously in the next several years [18-20]. To provide a scientific basis for designing effective mitigation measures to prevent India from becoming the next super emitter, it is necessary to further understand the temporal change in India's emissions at the sectoral level from both the production and consumption perspectives.

Two methods have been widely used to compile emission inventories: productionbased and consumption-based accounting methods. Production-based emissions, which were utilized in the United Nations Framework Convention on Climate Change and the Kyoto Protocol, allowed a country to undertake the responsibility of emissions caused by domestic demand associated with exports without considering imports [21, 22]. However, international trade has caused the geographic separation of producers and consumers and provided a path for producers to circumvent the responsibility of mitigating emissions by importing carbon-intensive products [23-25]. Under these circumstances, the consumptionbased accounting principle, which stipulates that a country should undertake responsibility for its emissions, including domestic demand and imports but excluding exports, can be used to trace emissions to final consumers through the multi-regional supply chain and thus to avoid carbon leakage [26-28]. 
Many studies have compared these two accounting principles [29-31]. Under the production principle, developed economies (e.g., the United States and the European Union) can reduce domestic emissions by importing carbon-intensive products from developing economies (e.g., China and India), placing an unreasonable burden of responsibility on emerging economies [32-34]. If we applied the consumption principle, then developing countries would have a negative incentive to improve their low-carbon techniques because they would not need to shoulder the full responsibility for emissions; thus, this principle would be detrimental to the profits of developed countries [35, 36]. Furthermore, researchers have calculated and compared the emissions resulting from the production and consumption principles at the global and national levels, and the findings illustrated that over the last two decades, developed economies have been net importers of emissions in international trade and developing economies have been net exporters because their products feature lower technologies and higher emission intensities [37-39]. The scale of emissions flowing from developing economies to developed economies increased from 2000 to 2011, with most of them embodied in intermediate products as a result of the deep convergence of the global economy [32, 40, 41].

Existing studies of the emissions embodied in India's international trade have provided a good starting point. Some researchers have estimated emissions based on India's inputoutput tables in 1991 and 1996 and found that India was a net importer because exports were dominated by low-intensity products (e.g., food and textiles) and imports were dominated by high-intensity products (e.g., iron and steel) [42-44]. However, this trend has reversed in recent years because of the increasing share of high-intensity products in India's exports and the rise of South-South trade [14, 45, 46]. Most of those studies focused on the scale and its changes in emissions induced by production and consumption in India but paid less attention to the link between original emitters in India and final consumers in other countries. Therefore, there remains a gap in tele-connection from direct emitters in India to final consumers in other regions, the opposite flow, and the temporal change.

In this study, we present a framework to trace the emissions from the original emitters in India to the final consumers in other regions, as well as from the final consumers in India to the original emitters in other regions. With this framework, we assess India's time-series domestic-demanded, exported and imported emissions embodied in final and intermediate products. Then, the total emission intensities of products produced in India were calculated. Based on this foundation, we trace the emissions from the consuming countries to the original emitters and analyze the emission flows between India and its main partners.

This paper is organized as follows. In Section 2, we describe our framework for the environmentally extended multi-regional input-output model, including the sources and treatment of the raw data. In Section 3, we present a time-series of production-based and consumption-based emissions in India, calculate the total emission intensities of products produced in India, and finally trace the flows of exported and imported emissions in India. In Section 4, we discuss the new findings and their policy implications.

\section{Methodology and data}

\subsection{Multi-regional input-output analysis}

A popular method for calculating the emissions embodied in trade is the multiregional input-output model, which illustrates the inter-industry relations in supply chains 
and links the production and consumption in different countries to an economic system through international trade [47-49].

Suppose that there are $m$ countries or regions and that each has $n$ sectors in the international economic system. In addition, $z_{i j}^{p q}(p, q=1,2, \ldots m ; i, j=1,2, \ldots n)$ indicates that industry $j$ in country $q$ consumes the product of industry $i$ in country $p$ during its production process; $y_{i}^{p q}$ indicates that country $q$ consumes the final product from industry $i$ in country $p$; and $x_{i}^{p}$ represents the total output of industry $i$ in country $p$. Then, we have the following:

$$
\sum_{q=1}^{m} \sum_{j=1}^{n} z_{i j}^{p q}+\sum_{q=1}^{m} y_{i}^{p q}=x_{i}^{p}
$$

A technical coefficient named $a_{i j}^{p q}=z_{i j}^{p q} / x_{j}^{q}$ is defined, and it represents the inputs from industry $i$ in country $p$ to produce one unit of product by sector $j$ in country $q$. Then, Eq. (1) can be formulated as follows:

$$
\mathbf{X}=(\mathbf{I}-\mathbf{A})^{-1} \mathbf{Y}
$$

where $\mathbf{X}=\left(x_{i}^{p}\right), \mathbf{A}=\left(a_{i j}^{p q}\right)$, and $\mathbf{Y}=\left(y_{i}^{p q}\right) . \mathbf{L}=(\mathbf{I}-\mathbf{A})^{-1}$ represents the Leontief inverse matrix, which embodies the direct and indirect inputs into the production process of the final products.

We define the direct emission intensity, which represents the direct emissions emitted by the original sectors when producing per-unit output. The direct emission intensity of industry $j$ in country $p$ can be expressed as $D_{j}^{p}=e_{j}^{p} / x_{j}^{p}$, where $e_{j}^{p}$ represents the carbon emissions of industry $j$ in country $p$. The emissions embodied in exports from country $p$ to country $q$ can be written as follows:

$$
E^{p q}=D^{p} L Y^{q}=D^{p} L Y^{p q}+D^{p} L Y^{\widetilde{p q}}=E_{f}^{p q}+E_{r}^{p q}
$$

where $\mathbf{D}^{\mathbf{p}}$ represents the direct emission intensity for country $p$ but zero for all other countries; $\mathbf{Y}^{\mathbf{p q}}$ represents the final demand of country $q$ from country $p$ but zero for all other countries; $\mathbf{Y}^{\widetilde{\mathbf{p}} \mathbf{q}}$ represents the final demand of country $q$ from all countries but zero for country $p$; and $\mathbf{E}_{\mathbf{f}}^{\mathbf{p q}}, \mathbf{E}_{\mathbf{r}}^{\mathbf{p q}}$ represent the emissions embodied in final, intermediate products export from country $p$ to country $q$, respectively. $P=q$ represents the emissions embodied in domestic demand in country $p$.

Meanwhile, we can reallocate the exported emissions from country $p$ to country $q$ to the original emitters as follows:

$$
\mathbf{E}^{\mathbf{p q}}=\widehat{\mathbf{D}}_{\mathbf{L}} \mathbf{Y}^{\mathbf{q}}
$$

where $\widehat{\mathbf{D}^{\mathbf{p}}}$ represents the diagonal matrix of $\mathbf{D}^{\mathbf{p}}$.

By incorporating a vector of direct emission intensity, the total emission intensity, which includes the direct emissions emitted by the original sectors on site and the indirect emissions from the inputs from other sectors or regions through the domestic and international supply chain of the per-unit final products [50-52], can be calculated as follows:

$$
\mathbf{T}=\widehat{\mathbf{D}} \mathbf{L}
$$

where $\mathbf{D}$ represents the direct emission intensity for all countries.

\subsection{Data sources}

This study requires two sets of data: the multi-regional input-output tables and the production-based carbon emission inventory. The multi-regional input-output tables are from the World Input-output Database [53], which includes 44 countries or regions and 56 
industrial sectors, from 2000 to 2014 . We adjust the monetary data in the World Inputoutput Database by using the constant prices from 2000 to provide a consistent analysis. The carbon emissions from fossil fuel (e.g., coal, oil and gas) combustion are derived from the International Energy Agency [4], and these emission data include 143 countries or regions and 32 industrial sectors. Because a one-to-one match is not always observed among the sectors in the International Energy Agency and the World Input-output Database, we adjust the emissions in the International Energy Agency into the World Input-output Database sectoral classification based on the fourth revision of International Standard Industrial Classification to compile a time-series production-based emission inventory (see Table A1 in the Appendix for detailed information). Two typical relationship types appeared in the matching process: one-to-many and many-to-one. For one-to-many, we use the output in the World Input-output Database as a weight to allocate the emissions. For many-to-one, we add all the emissions together.

\section{Results and discussion}

\subsection{Demand-driven $\mathrm{CO}_{2}$ emissions in India}

From the production perspective, emissions continuously increased by $6 \%$ per year from 890.4 Mt in 2000 to 2019.7 Mt in 2014 (Fig. 2). In 2000, 122.1 Mt of emissions were caused by foreign demand (Fig. $2 \mathrm{~b}$ and c), and this scale incessantly increased to $327.4 \mathrm{Mt}$ in 2014 at an annual growth rate of $6.8 \%$. In accordance with the rapid development of India's trade, the share of exported emissions increased from $13.7 \%$ in 2000 to $17.1 \%$ in 2008. However, this value decreased to $16.2 \%$ in 2014 because India's recovery speed was faster than that of the world, and India needed more materials and products to meet its domestic demand [54].

From the consumption perspective, emissions increased by $5.9 \%$ per year from 831 Mt in 2000 to $1871.4 \mathrm{Mt}$ in 2014. In 2000, 7.5\% (62.7 Mt) of consumption-based emissions were originally emitted abroad and finally consumed in India, and this value increased to $16.0 \%(251.81 \mathrm{Mt})$ in 2010 because of the large-scale domestic demand for products as a result of India's rapid urbanization and increasing population [55, 56]. However, the imported emissions decreased to $9.6 \%(179.03 \mathrm{Mt})$ in 2014 due to the growing industrial strength and increasing tariffs on imports after the implementation of the economic stimulating plan in 2009 [7, 8], which drove product providers to satisfy India's demand, which had transferred from abroad to the homeland.

Exported emissions were larger than imported emissions in 2000-2014. The netexported emissions witnessed a small decline from 59.5 Mt in 2000 to $22.6 \mathrm{Mt}$ in 2010 because of the stagnant secondary industry and India needed to import many necessities (e.g., furniture) to meet increasing demands of daily life [57]. However, this dilemma was reversed after 2010 due to India's government strongly supporting the development of secondary industry, and the net-exported emissions increased to $148.3 \mathrm{Mt}$ in 2014.

According to the deep integration of the Indian and the world economies, intermediate products played an important role in exported and imported emissions. In 2000, $60 \%$ of exported emissions were embodied in intermediate products. This share increased to $66.4 \%$ in 2007 and then decreased to $61.3 \%$ in 2009 because India's domestic and international supply chain became heavily influenced by the economic crisis. Similarly, $75.7 \%$ of imported emissions were embodied in intermediate products in 2007. This share decreased to $71.5 \%$ in 2009 and then increased to $79.4 \%$ in 2014 . Meanwhile, the intermediate 
products were more vulnerable to economic fluctuations. For example, the imported emissions embodied in intermediate products decreased by 6.5 Mt from 2007 to 2008, which was larger than that of final products $(0.2 \mathrm{Mt})$.

Most domestic-demanded, exported and imported emissions were embodied in manufacturing. The share of manufacturing in domestic-demanded and imported emissions increased from $34.5 \%$ and $57.2 \%$ in 2000 to $36.9 \%$ and $63.1 \%$ in 2014 , respectively. Many manufacturing products were in the furniture $(28.1 \%)$ and food $(16.3 \%)$ industries, illustrating the poor manufacturing capacity in India, which needed to import massive daily necessities to meet the needs of the increasing population and rapid urbanization. In contrast, the share of manufacturing in exported emissions increased from $42.6 \%$ in 2008 to $50.7 \%$ in 2014 . Most of the manufacturing products were textiles, which shows that increasing resource-intensive and labor-intensive products were outsourced to India in recent years, and India began to play the role of world manufactory, after China.

Another important player in domestic-demanded and imported emissions was construction, whose amount of these emissions increased from 126.6 Mt in 2000 to 348.7 Mt in 2014, at an annual growth rate of $7 \%$, due to the continuous improvement of infrastructure in India. Moreover, the second largest contributor of exported emissions was commercial and public services, which increased from 29.6 Mt in 2000 to 83.9 Mt in 2011 and then decreased to $78.7 \mathrm{Mt}$ in 2014 because most commercial and public services focused on computer programming and information services $(44.4 \%)$, which were substituted by China's high-tech exports [14].

\subsection{Total emission intensities embodied in products produced by India}

The total emission intensity can capture both the emissions released in India and the amount emitted in other countries along the supply chain [58-60]. Fig. 3 presents the total emission intensities of the products produced in India from 2000 to 2014, which reflect the structure of the international supply chain of products.

The total emission intensity differs significantly among products. On average, electricity, gas and water $(27.6 \mathrm{~kg}$ per dollar) were the highest among the selected products due to the coal-fired dominated power plant in India, which would directly emit a large amount of emissions. This result was similar to the conclusion of previous studies $[61,62]$. Similarly, transportation consumed considerable amounts of oil and gas because of the road-dominated transport system in India [63], which led to its high total emission intensity ( $2.5 \mathrm{~kg}$ per dollar). However, the high total emission intensity in manufacturing $(2.4 \mathrm{~kg}$ per dollar) and construction (1.8 kg per dollar) industries were due to the need for many inputs of raw material (e.g., basic metal and electricity) in their production process, which would induce many indirect emissions.

Moreover, a large difference in the total emission intensity was observed for the same products in different years. The total emission intensity in the electricity, gas and water industries increased from $23.1 \mathrm{~kg}$ per dollar in 2002 to $30.2 \mathrm{~kg}$ per dollar in 2014 due to India's increasing proportion of coal-fired generation capacity, which increased from $54.1 \%$ in 2002 to $60.2 \%$ in 2014 [64]. The total emission intensity of the transportation sector had an increase in 2007-2011 as a result of the weak energy efficiency in road transportation due to the traffic jam caused by the increasing numbers of motor vehicles and backward highway facilities. Meanwhile, the total emission intensity of the manufacturing industry increased after 2009 because of India's expansion of heavy industry (e.g., metal), which would consume more energy than the light industry (e.g., rubber and plastic). 
Producing products that are finished in India causes emissions in the homeland and abroad through the international supply chain. For example, if one unit of manufacturing is produced in India, then $2.1 \mathrm{~kg}$ of emissions would be released domestically and $0.3 \mathrm{~kg}$ released abroad, which illustrates that international trade has exerted considerable influence on the allocation of emissions.

\subsection{India's exported emission flows from the original emitters to the final consuming countries}

Electricity, gas and water were the major emitters of exported emissions in India in 2000-2014, followed by manufacturing (Fig. 4). In 2000, 55.9\% (68.3 Mt) of exported emissions were emitted by electricity, gas and water, $58 \%$ of which were linked to the final producer of manufacturing. This phenomenon was attributed to the major player of exports focused on manufacturing, especially textile and furniture, which were resource-intensive products and needed a lot of electricity input into its production process. The share of the electricity, gas and water industries in exported emissions stabilized around 51\% from 2009 to 2014 due to the increasing proportion of motor vehicles in exported manufacturing. These products demanded many raw materials (e.g., basic metal) to assemble and caused massive original emissions in manufacturing, the share of which in exported emissions increased from $25.1 \%$ in 2000 to $34.1 \%$ in 2014 . Meanwhile, another important receiver of exported emissions emitted by the electricity, gas and water industries was commercial and public services, the share of which increased from $23.9 \%$ in 2000 to $25.5 \%$ in 2014 due to the increasing share of computer programming and information services in exported products, which required many inputs of electricity.

The important receivers of India's exported emissions from 2000 to 2014 were the European Union and the United States; however, their share continuously decreased from $49 \%$ in 2000 to $30.3 \%$ in 2014 . This decrease was attributed to the exports becoming dominated by low-technology manufacturing products (e.g., textile and leather), which did not match the demand in developed countries. The exports of high-technology and highvalue-added products (e.g., information services) decreased after 2011 due to the replacement of China. Meanwhile, the proportion of emissions exported to China increased from $2.7 \%$ in 2000 to $7.5 \%$ in 2014 due to the country's massive population, which demanded many necessary products (e.g., textile and leather).

\subsection{India's imported emission flows traced from imports to the original emitters}

Developing countries were the main sources of India's imported emissions, and their share increased over time because most of the imported emissions were embodied in resource-intensive manufacturing products (e.g., furniture and machinery). Russia (8 Mt) was the largest supplier of India's imported emissions in 2000, and this role subsequently transferred to China because of the recombination of the global supply chain. China became the world manufactory of labor-intensive and resource-intensive products (e.g., textiles and leather). Meanwhile, $21.5 \%$ of India's imported emissions were linked to the final producer in developed countries (including the United States, the European Union and Japan) in 2000, and this proportion continuously decreased to $12.1 \%$ in 2014 . This decrease was attributed to the products produced in developed countries being concentrated in high-end manufacturing and high-value-added services, which were not consistent with the current demand in India.

The distribution of original emitters differed between developed and developing 
countries. For example, for the products ultimately consumed in India in $2000,31.5 \%$ of emissions were directly emitted by the electricity, gas and water industries in the European Union, and this proportion remained around 35\% from 2009 to 2014 (Fig. 5). By comparison, for the products ultimately consumed in the European Union in 2000, 55.9\% of emissions were directly emitted by the electricity, gas and water industries in India, and this proportion remained around 51\% from 2009 to 2014 (Fig. 4), which was higher than that of the European Union. This comparison illustrated the weak energy mix and backward low-carbon technologies in India.

\subsection{Comparison of emission flows embodied in trade between India and its major partners}

The responsibility for mitigating emissions among countries can be determined by measuring the redistribution of emissions caused by international trade [45, 65]. Fig. 6 presents the volume of emission flows between India and its primary partners.

The United States and the European Union were the major receivers of emissions outflowed from India in 2000-2014. The scale of emissions flowing into the United States decreased from $24.7 \mathrm{Mt}$ in 2000 to $22.9 \mathrm{Mt}$ in 2009 because of the weak domestic demand caused by the international financial crisis. This volume rapidly increased to $37.4 \mathrm{Mt}$ in 2014 with the resurgence of the United States economy and the demand for many products (e.g., textiles and leather) to meet the improving quality of life. Meanwhile, the scale of emissions flowing into the European Union rapidly increased from 23.4 Mt in 2000 to 37.0 Mt in 2009 and then decreased to $32.2 \mathrm{Mt}$ in 2011 because of the poor economic situation caused by the escalation of the European debt crisis; it subsequently increased to $44.4 \mathrm{Mt}$ in 2014. In contrast, Russia (5.7 Mt) was the largest source of emissions flowing into India in 2000, and this role was subsequently transferred to China due to its lower cost of products. However, the volume of emissions flowing into India from China decreased from $42.5 \mathrm{Mt}$ in 2011 to $25.0 \mathrm{Mt}$ in 2014 due to the recombination of the international supply chain, and many necessities demanded in India were produced domestically. In addition, Australia (10.4 Mt) surpassed Russia (5.6 Mt) to become the second largest source of emissions flowing into India in 2009, and this level rapidly decreased in 2011 due to its replacement of China. However, India reversed course and became a net exporter of emissions when trading with Australia in 2014, although its emission volume was small $(0.6 \mathrm{Mt})$.

Manufacturing played an important role in emission flows, but its departmental distribution had significant differences in outflows from and inflows into India. For example, $52.1 \%$ of emissions flowing into the European Union from India in 2009 were embodied in manufacturing, and this proportion continuously increased to $57.3 \%$ in 2014 because most of the manufacturing products were necessities (e.g., textiles and leather) with low demand elasticity. By comparison, in 2009, 88.4\% of the emissions flowing into India from China were embodied in manufacturing, which also held an absolute advantage, even though its share decreased to $82.9 \%$ in 2014 . Many of the manufacturing products were in the machinery and equipment industries $(19.4 \%$ on average) because of the rapid industrialization and urbanization in India.

\section{Conclusions and policy implications}

In this paper, we use the production-based and consumption-based perspectives to calculate the exported and imported emissions in India from 2000 to 2014 by using a multi- 
regional input-output model based on data from the World Input-output Database and the International Energy Agency. Then, we measure the total emission intensities of the products produced by India. Furthermore, we trace the exported and imported emissions from the original emitters to the final consumers through the international supply chain. Finally, we analyze the sources and destinations of the emission flows embodied in exports and imports within India's economy.

The results indicate that the emissions embodied in domestic consumption and exports increased rapidly from 2000 to 2014, while the imported emissions decreased from 2011 to 2014, which led to the growth of the net-exported emissions in the same period. The exported and imported emissions were contributed mainly by intermediate products, especially manufacturing products. The total emission intensity in the electricity, gas and water industries was the highest among the selected fields, followed by transportation and manufacturing. Meanwhile, the electricity, gas and water industries were the main emitter of India's exported emissions, many of which were linked to final consumers in the European Union and the United States, although these regions' share decreased over time. Russia was the major source of India's imported emissions in 2000, and this rank was subsequently assumed by China.

The detailed analysis of India's emission features implies that the following potential emission reduction measures can be implemented.

(1) Approximately $39.7 \%$ of production-based emissions were embodied in manufacturing products in 2000-2014, and this dominant position will be strengthened in future years due to the rapid development of secondary industry in India. Therefore, India should encourage research in low-carbon technology by increasing investments and subsidies for the industry [66-68]. For example, the energy efficiency in the production process of raw materials in the upstream manufacturing supply chain could be improved. Meanwhile, the management of the utilization of these materials could be strengthened to avoid waste and to establish a green domestic supply chain in India. Furthermore, India could transfer its industrial structure and shift its position in the international supply chain by developing technology-intensive and high-value-added manufacturing (e.g., precision machinery), thereby decreasing the exported emissions of intermediate products.

(2) More than half of India's production-based emissions were originally emitted by the electricity, gas and water industries in 2000-2014 because of the industries' carbonintensive energy portfolio. Therefore, a better way to decrease emissions in the electricity, gas and water industries is to replace coal-fired generator sets with nuclear power plants. Meanwhile, renewable energy could be developed and the proportion of wind and solar power could be improved. Furthermore, India could apply ultra-high voltage technology in the transmission of electrical energy to reduce losses and improve its utilization ratio, as achieved in China.

(3) Many consumption-based emissions are embodied in construction, and this share has increased over time because of the rapidly expanding infrastructure to support urbanization in India. Therefore, India could develop low-carbon cities by adopting recyclable and clean materials in construction, thereby decreasing emissions in the upstream industries. Meanwhile, the utilization efficiency of construction materials could be improved, and green infrastructure could be built.

(4) The European Union and the United States were the major economies outsourcing emissions to India, and this volume has increased over time. Meanwhile, when producing 
the same quantity and type of products, more emissions were emitted in India than in developed countries due to India's lower energy efficiency. Globally, emissions have not decreased but were redistributed among countries, which was referred to as the "beggarthy-neighbor" effect [69]. Therefore, it would be beneficial for India to participate in international cooperative mitigation actions (e.g., the Clean Development Mechanism) to obtain technical and financial support. Furthermore, India could become more deeply involved in the Silk Road Economic Belt and the 21st Century Maritime Silk Road (the Belt and Road), a framework for economic cooperation, and strive for more technology transfers from the European Union.

\section{Acknowledgments}

This work was supported by the National Key R\&D Program of China (2016YFA0602604), the Natural Science Foundation of China (71533005, 41629501, 71773075 and 71373153), Chinese Academy of Engineering (2017-ZD-15-07), the UK Economic and Social Research Council (ES/L016028/1), Natural Environment Research Council (NE/N00714X/1 and NE/P019900/1), the Economic and Social Research Council (ES/L016028/1), a British Academy Grant (AF150310).

\section{References}

[1] Patz, J. A., Frumkin, H., et al. Climate Change: Challenges and Opportunities for Global Health. Jama 2014;312:1565-1580.

[2] Moser, S. C. Communicating Climate Change: History, Challenges, Process and Future Directions. Wiley Interdisciplinary Reviews: Climate Change 2010;1:31-53.

[3] IPCC. Contribution of Working Groups I, II and III to the Fifth Assessment report of the Intergovernmental Panel on Climate Change. Climate Change 2014: Synthesis Report. 2014.

[4] IEA. $\mathrm{CO}_{2}$ Emissions from Fuel Combustion. 2017.

[5] UNFCCC, V. Adoption of the Paris Agreement. United Nations. 2015.

[6] India. Statistical Yearbook India. 2017. < http://www.mospi.gov.in/statistical-year-book-india/2017>

[7] Kumar, R. Global Financial and Economic Crisis: Impact on India and Policy Response. United Nations Development Programme. 2009.

[8] Subbarao, D. Impact of the Global Financial Crisis on India Collateral Damage and Response. 2009.

[9] Veda, Y. India's Intended Nationally Determined Contribution: Working Towards Climate Justice. UNFCCC. 2015.

[10] Wei, S. Enhanced Actions on Climate Change: China's Intended Nationally Determined Contributions. UNFCCC. 2015.

[11] Mi, Z., Meng, J., et al. Pattern Changes in Determinants of Chinese Emissions. Environmental Research Letters 2017;12:074003.

[12] Zheng, H., Shan, Y., et al. How Modifications of China's Energy Data Affect Carbon Mitigation Targets. Energy Policy 2018;116:337-343.

[13] Jiang, X., Chen, Q., et al. Revisiting the Global Net Carbon Dioxide Emission Transfers by International Trade: the Impact of Trade Heterogeneity of China. Journal of Industrial Ecology 2016;20:506-514.

[14] Meng, J., Mi, Z., et al. The Rise of South-South Trade and Its Effect on Global $\mathrm{CO}_{2}$ Emissions. Nature communications 2018;9:1871.

[15] Shan, Y., Guan, D., et al. China $\mathrm{CO}_{2}$ Emission Accounts 1997-2015. Scientific data 2018;5:170201.

[16] Mi, Z., Meng, J., et al. China's "Exported Carbon" Peak: Patterns, Drivers, and Implications. Geophysical Research Letters 2018;45:4309-4318.

[17] Guan, D., Meng, J., et al. Structural Decline in China's $\mathrm{CO}_{2}$ Emissions through Transitions in Industry and Energy Systems. Nature Geoscience 2018:1.

[18] Garg, A., Shukla, P., et al. $\mathrm{CO}_{2}$ Emission in India: Trends and Management at Sectoral, Sub-regional and Plant Levels. Carbon Management 2017;8:111-123. 
[19] Johansson, D. J. A., Lucas, P. L., et al. Multi-model comparison of the economic and energy implications for China and India in an international climate regime. Mitigation \& Adaptation Strategies for Global Change 2015;20:1335-1359.

[20] Anandarajah, G., Gambhir, A. India's $\mathrm{CO}_{2}$ emission Pathways to 2050: What Role Can Renewables Play? Applied energy 2014;131:79-86.

[21] UNFCCC. United Nations Framework Convention on Climate Change. United Nations. 1992.

[22] Telesetsky, A. The Kyoto Protocol. Ecology Law Quarterly 1999;26:797-813.

[23] Su, B., Ang, B. Input-output Analysis of $\mathrm{CO}_{2}$ Emissions Embodied in Trade: A Multi-region Model for China. Applied Energy 2014;114:377-384.

[24] Sun, X., Li, J., et al. Energy Implications of China's Regional Development: New Insights from Multiregional Input-output Analysis. Applied energy 2017;196:118-131.

[25] Duan, C., Chen, B., et al. Interregional Carbon Flows of China. Applied Energy 2018.

[26] Li, J. S., Zhou, H., et al. Carbon Emissions and Their Drivers for A Typical Urban Economy from Multiple Perspectives: A Case Analysis for Beijing City. Applied Energy 2018;226:1076-1086.

[27] Sun, Y., Kang, C., et al. Analysis of Transmission Expansion Planning Considering Consumption-based Carbon Emission Accounting. Applied energy 2017;193:232-242.

[28] Wang, S., Liu, Y., et al. Multiregional Input-output and Ecological Network Analyses for Regional Energy-Water Nexus within China. Applied Energy 2017.

[29] Shao, L., Li, Y., et al. Carbon Emission Imbalances and the Structural Paths of Chinese regions. Applied Energy 2018;215:396-404.

[30] Nakano, S., Okamura, A., et al. The Measurement of $\mathrm{CO}_{2}$ Embodiments in International Trade: Evidence from the Harmonised Input-Output and Bilateral Trade Database. OECD Science Technology \& Industry Working Papers. 2009.

[31] Zhang, B., Qiao, H., et al. Growth in Embodied Energy Transfers via China's Domestic Trade: Evidence from Multi-regional Input-output Analysis. Applied energy 2016;184:1093-1105.

[32] Zhang, W., Peng, S. Analysis on $\mathrm{CO}_{2}$ Emissions Transferred from Developed Economies to China through Trade. China \& World Economy 2016;24:68-89.

[33] Weber, C. L., Peters, G. P., et al. The Contribution of Chinese Exports to Climate Change. Energy Policy 2008;36:3572-3577.

[34] Skelton, A., Guan, D., et al. Mapping Flows of Embodied Emissions in the Global Production System. Environmental Science \& Technology 2011;45:10516-10523.

[35] Proops, J. L., Atkinson, G., et al. International Trade and the Sustainability Footprint: A Practical Criterion for Its Assessment. Ecolog. Econ. 1999;28:75-97.

[36] Ferng, J. J. Allocating the Responsibility of $\mathrm{CO}_{2}$ Over-emissions from the Perspectives of Benefit Principle and Ecological Deficit. Ecolog. Econ. 2003;46:121-141.

[37] Arce, G., López, L. A., et al. Carbon Emissions Embodied in International Trade: The Post-China Era. Applied energy 2016;184:1063-1072.

[38] Wiebe, K. S., Bruckner, M., et al. Carbon and Materials Embodied in the International Trade of Emerging Economies. Journal of Industrial Ecology 2012;16:636-646.

[39] Tian, J., Liao, H., et al. Spatial-temporal Variations of Embodied Carbon Emission in Global Trade Flows: 41 Economies and 35 Sectors. Natural hazards 2015;78:1125-1144.

[40] Boitier, $\mathrm{B} . \mathrm{CO}_{2}$ emissions production-based accounting vs consumption Insights from the WIOD databases. WIOD Conference Paper 2012.

[41] Peters, G. P., Minx, J. C., et al. Growth in Emission Transfers via International Trade from 1990 to 2008. Proceedings of the National Academy of Sciences 2011;108:8903-8908.

[42] Mukhopadhyay, K. Impact of Trade on Energy Use and Environment in India: An Input-Output Analysis. 2004.

[43] Mukhopadhyay, K., Chakraborty, D. Is Liberalization of Trade Good for the Environment? Evidence from India. Asia Pacific Development Journal 2005;12:109.

[44] Dietzenbacher, E., Mukhopadhyay, K. An empirical examination of the pollution haven hypothesis for India: towards a green Leontief paradox? Environ. Resource Econ. 2007;36:427-449.

[45] Davis, S. J., Caldeira, K. Consumption-based Accounting of $\mathrm{CO}_{2}$ Emissions. Proceedings of the National Academy of Sciences 2010;107:5687-5692.

[46] Fernández-Amador, O., Francois, J. F., et al. Carbon Dioxide Emissions and International Trade at the Turn of the Millennium. Ecolog. Econ. 2016;125:14-26.

[47] Meng, J., Liu, J., et al. Globalization and Pollution: Tele-connecting Local Primary $\mathrm{PM}_{2.5}$ Emissions to 
Global Consumption. Proceedings Mathematical Physical \& Engineering Sciences 2016;472:2195.

[48] Chen, B., Li, J., et al. Global Energy Flows Embodied in International Trade: A Combination of Environmentally Extended Input-output Analysis and Complex Network Analysis. Applied Energy 2018:210:98-107.

[49] Li, J. S., Chen, B., et al. Tracking Mercury Emission Flows in the Global Supply Chains: A Multiregional Input-output Analysis. Journal of Cleaner Production 2017;140:1470-1492.

[50] Meng, J., Liu, J., et al. The Impact of Domestic and Foreign Trade on Energy-related PM Emissions in Beijing. Applied energy 2016;184:853-862.

[51] Chen, B., Han, M., et al. Global Land-water Nexus: Agricultural Land and Freshwater Use Embodied in Worldwide Supply Chains. Science of the Total Environment 2018;613:931-943.

[52] Mi, Z., Zhang, Y., et al. Consumption-based Emission Accounting for Chinese Cities. Applied Energy 2016;184:1073-1081.

[53] WIOD. World Input-Output Database. 2016. $<\underline{\text { http://www.wiod.org/database/wiots16> }}$

[54] OECD. Economic Outlook for Southeast Asia, China and India 2014: Beyond the Middle-Income Trap. 2013.

[55] Ponce de Leon Barido, D., Marshall, J. D. Relationship between Urbanization and $\mathrm{CO}_{2}$ Emissions Depends on Income Level and Policy. Environmental science \& technology 2014;48:3632-3639.

[56] Wang, Y., Li, L., et al. Does Urbanization Lead to More Carbon Emission? Evidence from a Panel of BRICS Countries. Applied Energy 2016;168:375-380.

[57] Mehta, Y., Rajan, A. J. Manufacturing Sectors in India: Outlook and Challenges. Procedia engineering 2017;174:90-104.

[58] Meng, J., Liu, J., et al. Tracing Primary $\mathrm{PM}_{2.5}$ Emissions via Chinese Supply Chains. Environmental Research Letters 2015;10:054005.

[59] Chen, G. Q., Zhang, B. Greenhouse Gas Emissions in China 2007: Inventory and Input-output Analysis. Energy Policy 2010;38:6180-6193.

[60] Zhang, B., Qu, X., et al. Identifying Primary Energy Requirements in Structural Path Analysis: A Case Study of China 2012. Applied energy 2017;191:425-435.

[61] Sun, C., Ding, D., et al. Estimating the Complete $\mathrm{CO}_{2}$ Emissions and the Carbon Intensity in India: From the Carbon Transfer Perspective. Energy Policy 2017;109:418-427.

[62] Parikh, J., Panda, M., et al. $\mathrm{CO}_{2}$ Emissions Structure of Indian Economy. Energy 2009;34:1024-1031.

[63] Intelligence, M. Transportation Industry in India - Analysis of Growth, Trends and Forecast (2015 2020). $<$ https://www.mordorintelligence.com/industry-reports/analysis-of-transportation-industry-in-india $>$ [64] India. Annual Reports Year Wise (Ministry). 2014.

[65] Liu, Z., Feng, K., et al. Four System Boundaries for Carbon Accounts. Ecological modelling 2015;318:118-125.

[66] $\mathrm{Du}, \mathrm{K} ., \mathrm{Lu}, \mathrm{H}$., et al. Sources of the Potential $\mathrm{CO}_{2}$ Emission Reduction in China: A Nonparametric Metafrontier Approach. Applied Energy 2014;115:491-501.

[67] Fais, B., Sabio, N., et al. The Critical Role of the Industrial Sector in Reaching Long-term Emission Reduction, Energy Efficiency and Renewable Targets. Applied Energy 2016;162:699-712.

[68] Yang, Z., Zhao, Y. Energy Consumption, Carbon Emissions, and Economic Growth in India: Evidence from Directed Acyclic Graphs. Econ. Modelling 2014;38:533-540.

[69] Zhao, H. Y., Zhang, Q., et al. Assessment of China's Virtual Air Pollution Transport Embodied in Trade by Using A Consumption-based Emission Inventory. Atmospheric Chemistry and Physics 2015;15:54435456 . 


\section{Appendix}

Table A1

Mapping the sectors in the International Energy Agency and the World Input-output Database.

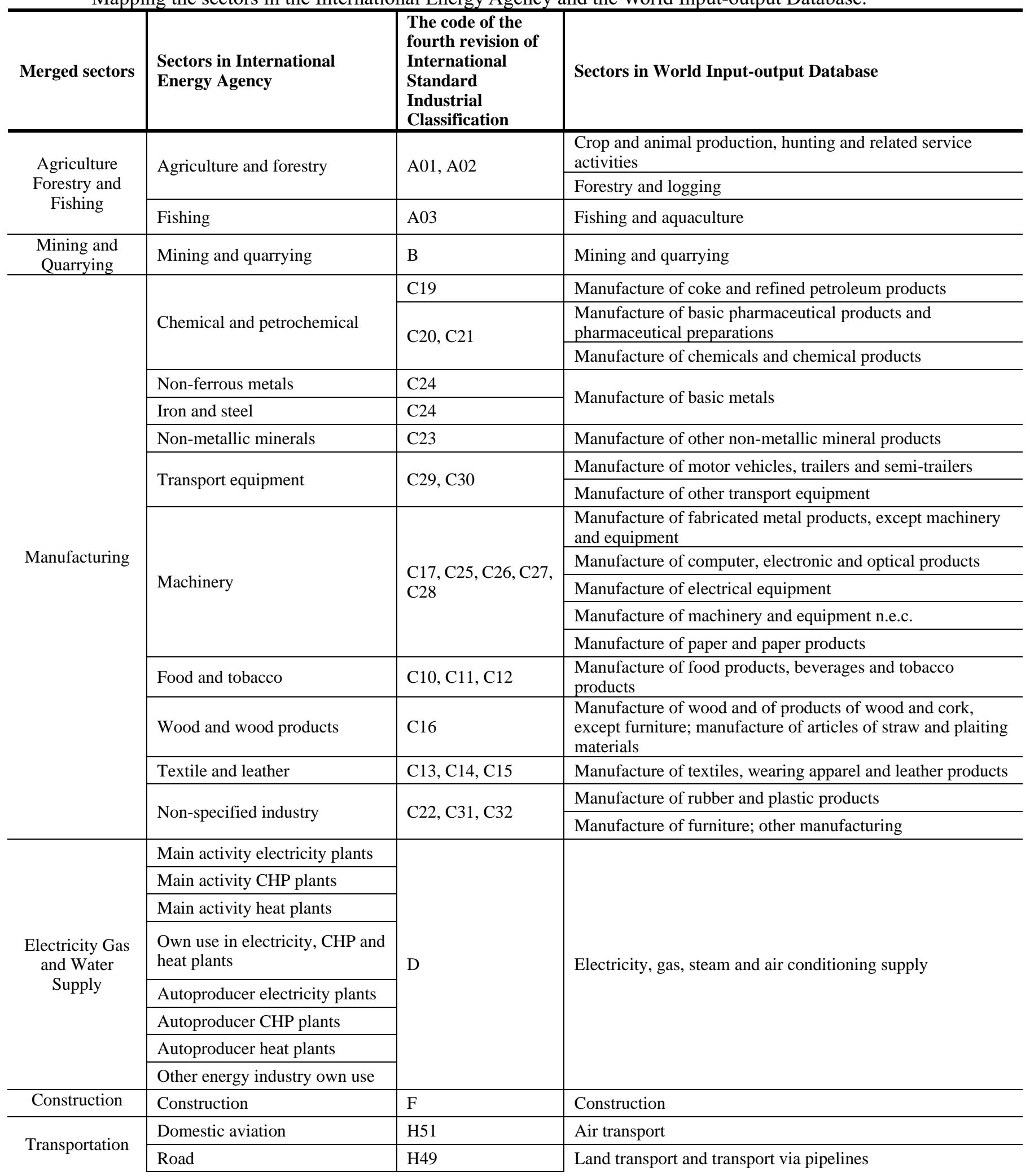




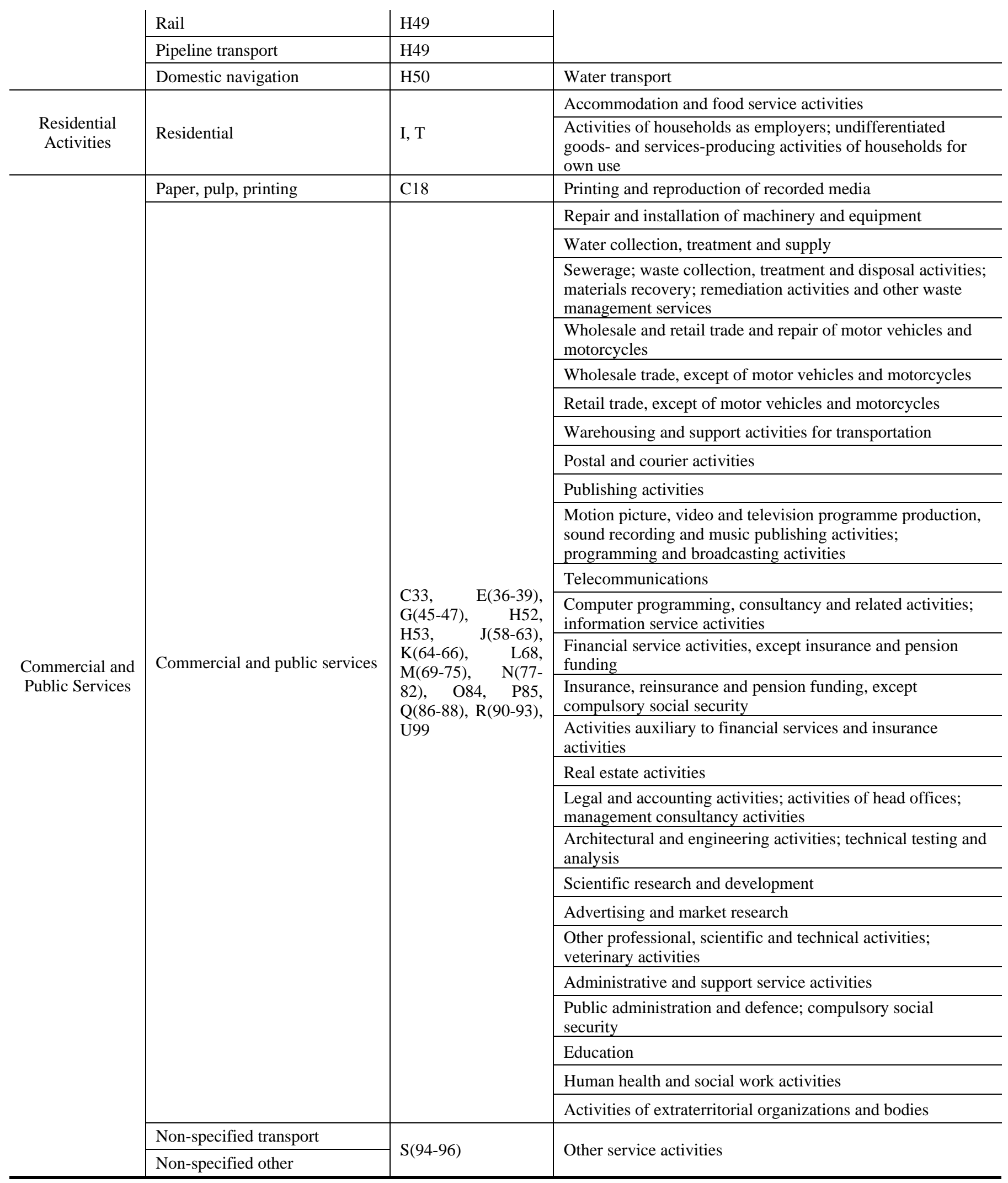




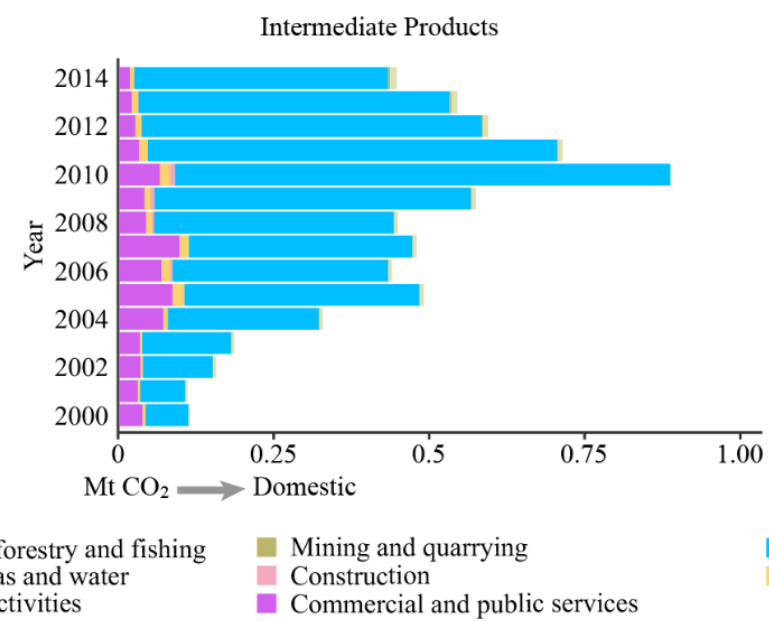

Manufacturing
Transportation

Agriculture, forestry and fishin

Electricity, gas and wate

- Commercial and public services

Fig. A1. Emissions embodied in domestic consumption of intermediate products from 2000 to 2014 . 


\section{Figures}
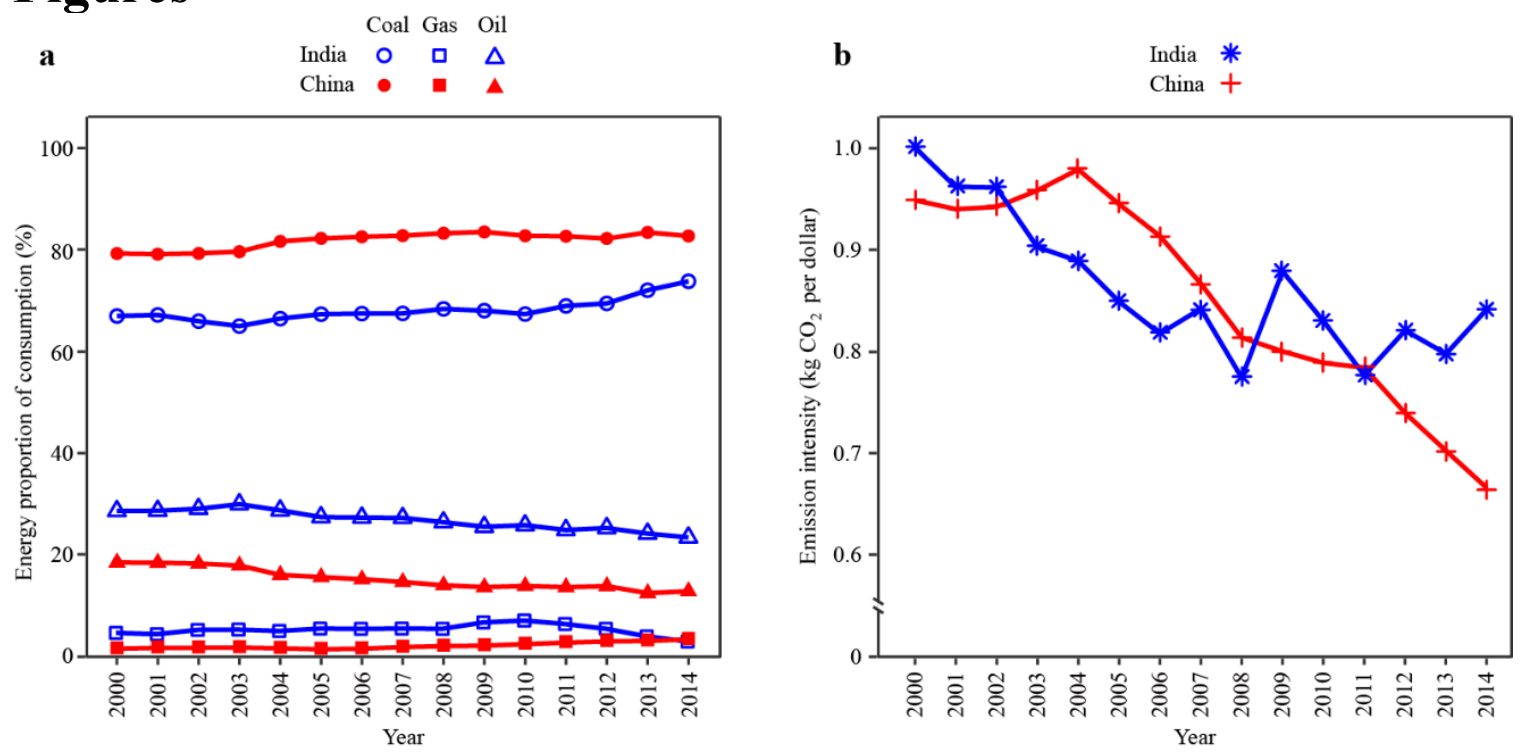

Fig. 1. Comparison of the emission circumstances in India (blue) and China (red). (a) Proportions of the emissions emitted by major energies. The data were obtained from a series of reports of $\mathrm{CO}_{2}$ emissions from fuel combustion. (b) The trend of emission intensity, which represents carbon emissions per unit of economic output, was calculated using the emissions divided by the output adjusted based on the constant price for the year 2000. The data were calculated by the authors. 

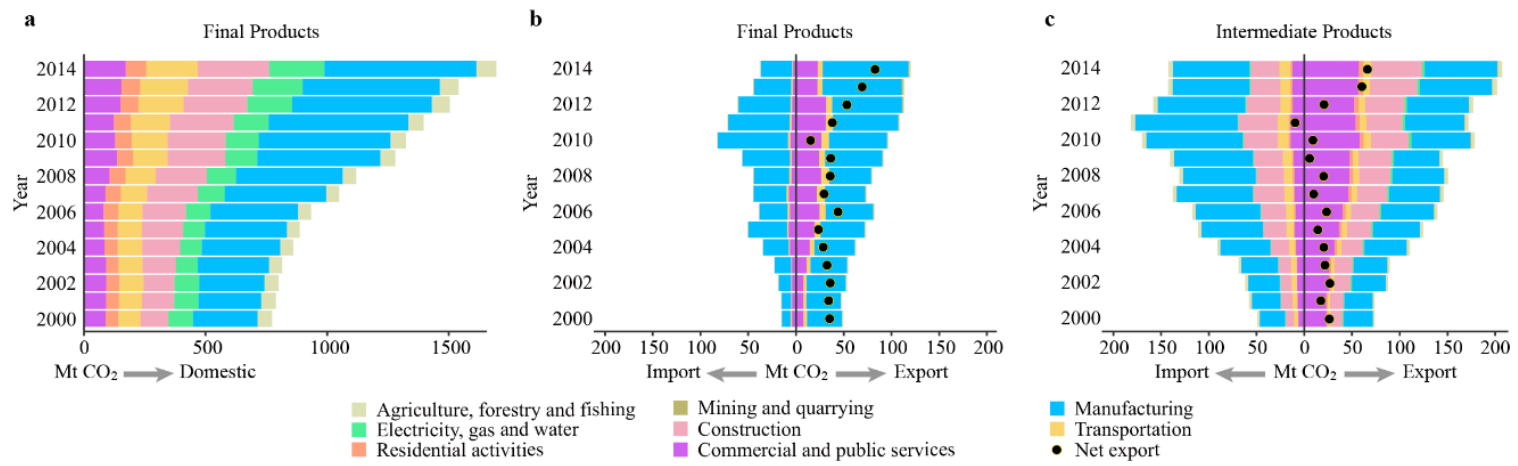

Fig. 2. Comparison of the production-based and consumption-based emissions in India from 2000 to 2014. Notably, the volume of domestic consumption of intermediate products is small (in the range of 0.1-0.9 Mt). See Fig. A1 in the Appendix for more detailed information. 

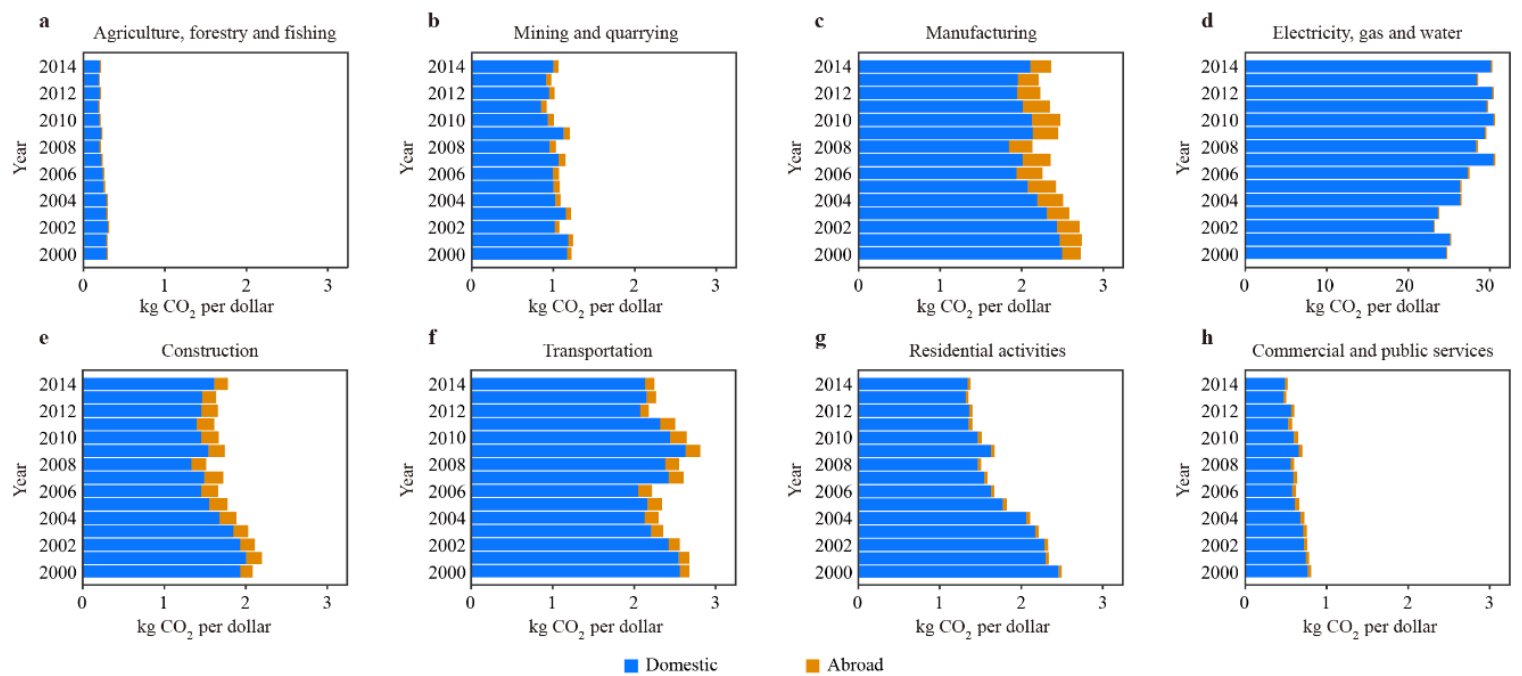

Fig. 3. Mean total emission intensities ( $\mathrm{kg} \mathrm{CO}_{2}$ per dollar) for the 8 aggregated sectors. See Table $\mathrm{A} 1$ in the Appendix for detailed information. The blue and orange colors represent the total emission intensities in India and abroad, respectively. 

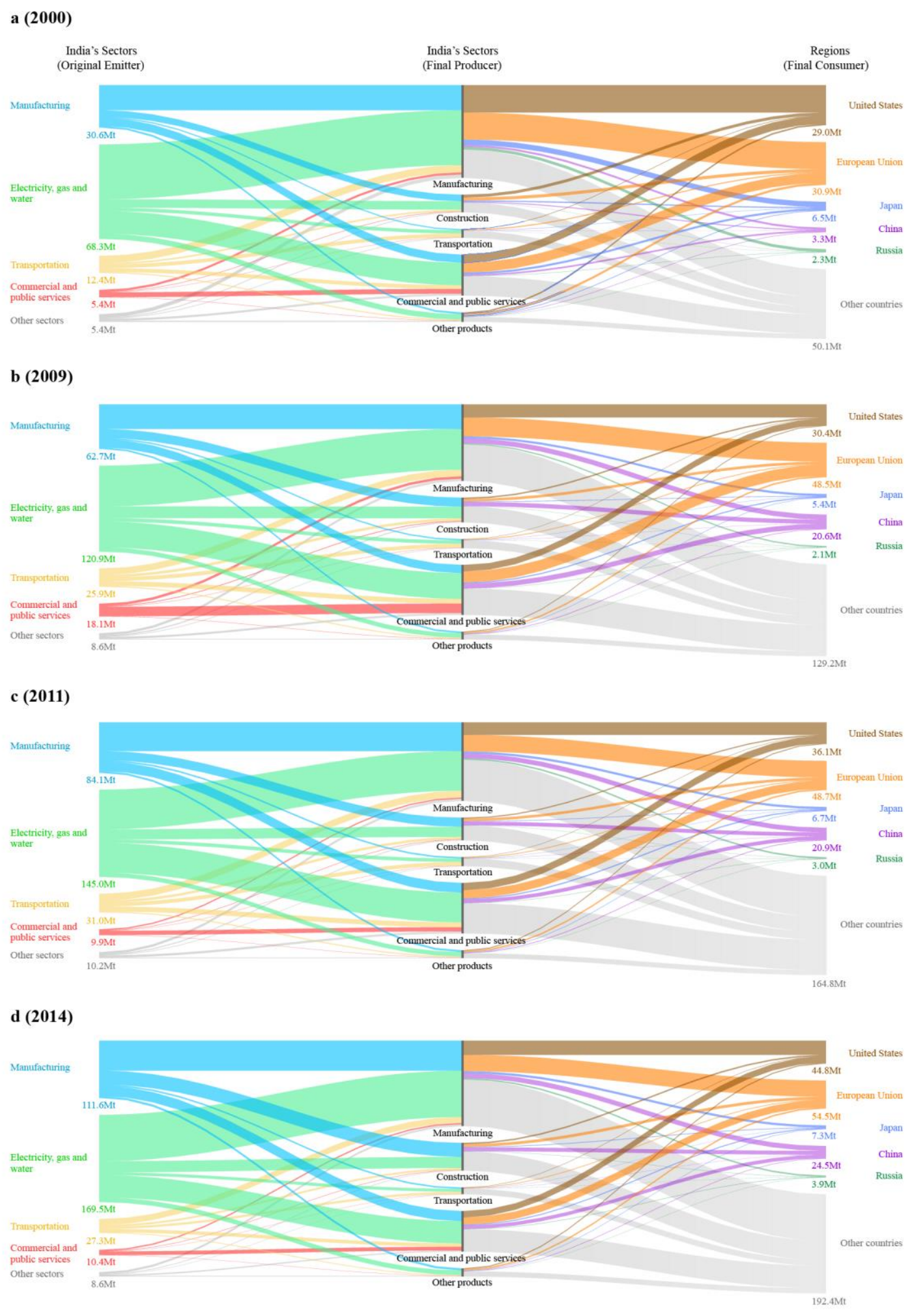

Fig. 4. Sankey diagram of India's exported emission flows from the original emitters to the final producers and, finally, to the consuming countries in (a) 2000; (b) 2009; (c) 2011 and (d) 2014. From left to right, the first layer represents the original emitters of exported emissions, the second layer represents the emissions embodied in final products, and the third layer represents the regions where the final products are consumed. The width of the flow represents the emissions. 


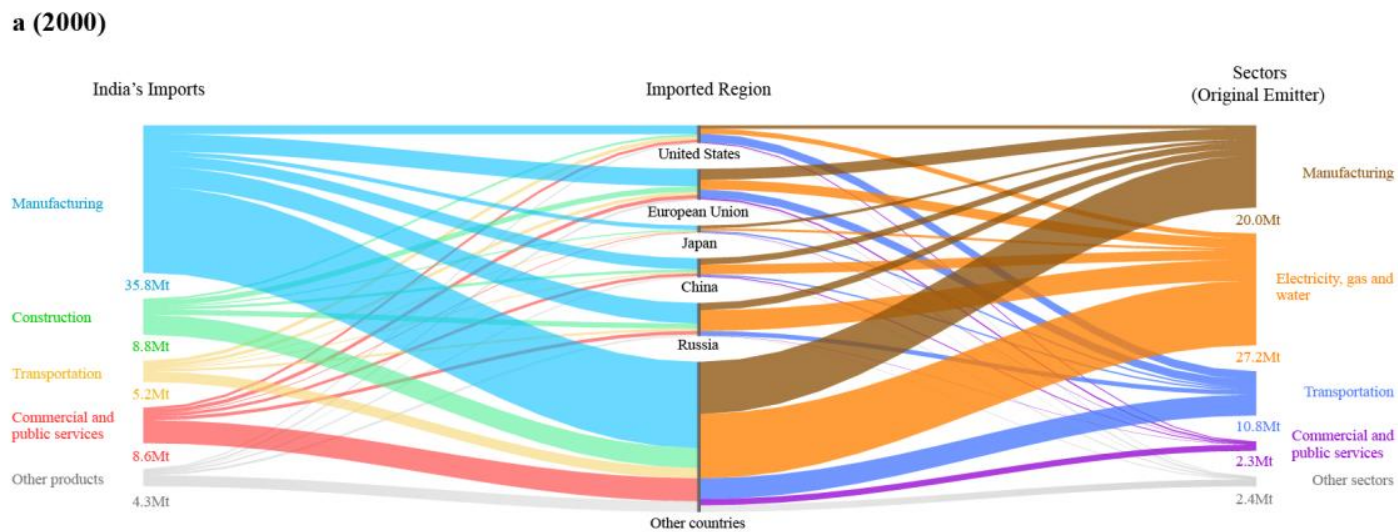

b (2009)
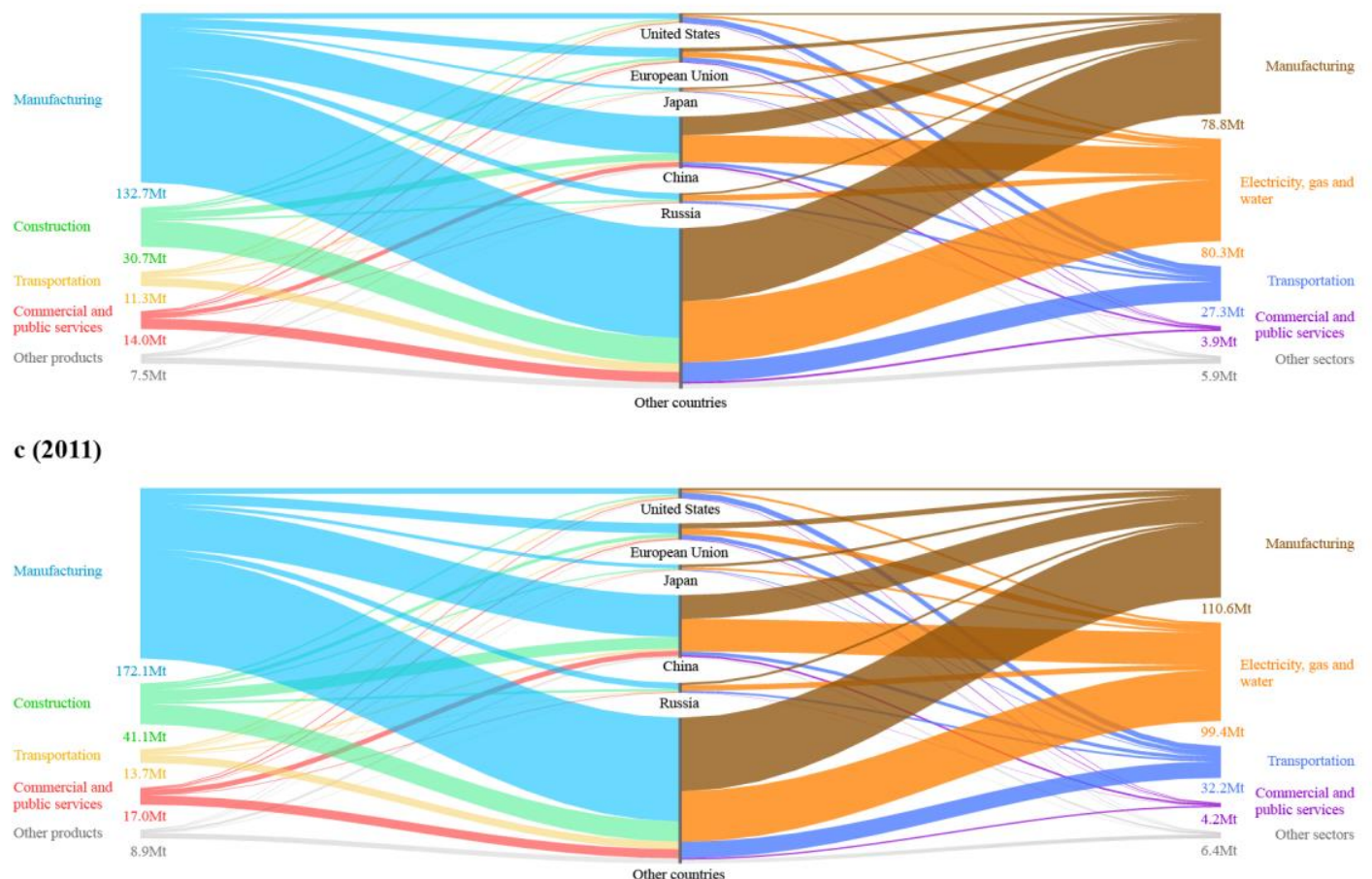

d (2014)

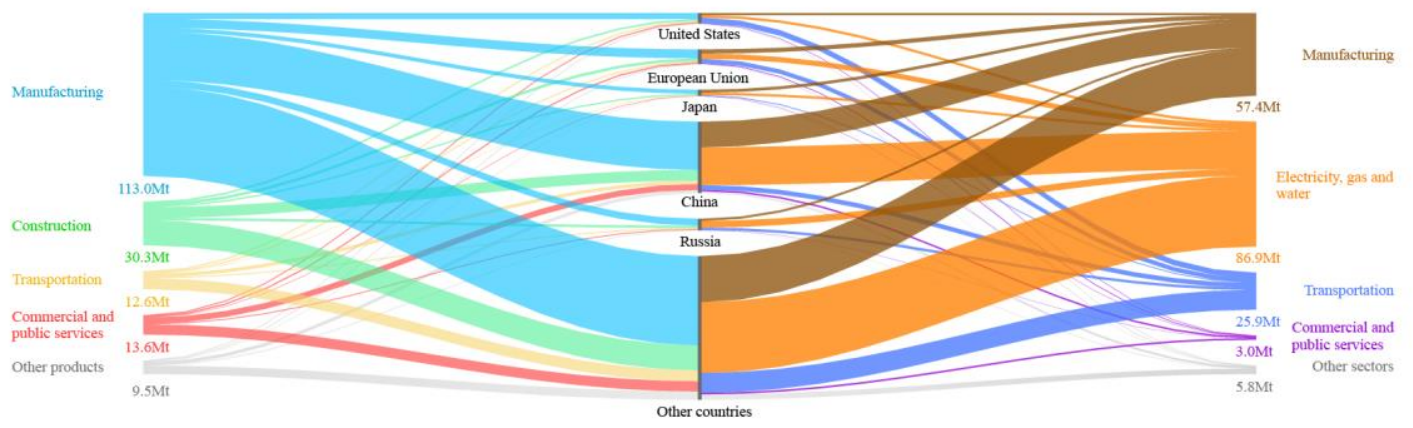

Fig. 5. Sankey diagram of India's imported emission flows traced from the imports to their imported regions and finally to the original emitters in (a) 2000; (b) 2009; (c) 2011 and (d) 2014. From left to right, the first layer represents the emissions embodied in imports, the second layer represents the regions where those imports were produced, and the third layer represents the original emitters of the emissions. The width of the flow represents the emissions. 
(a) 2000

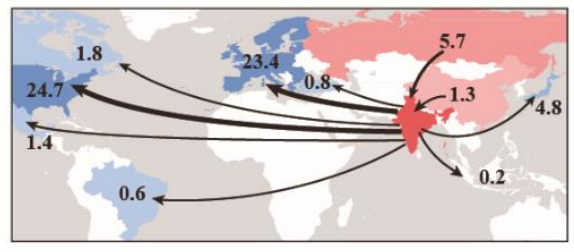

(c) 2011

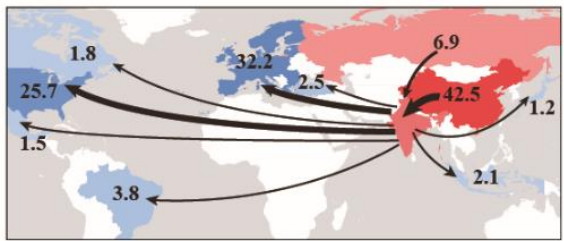

(b) 2009

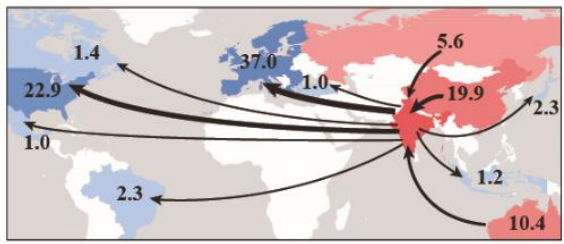

(d) 2014

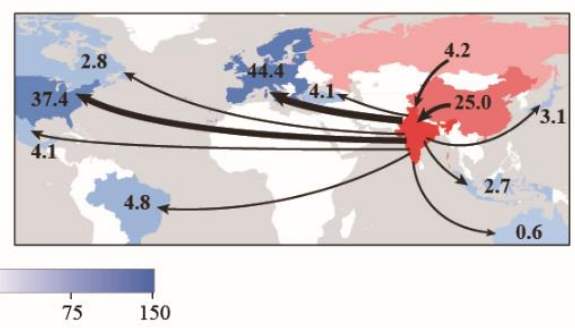

Fig. 6. Flows of emissions embodied in trade between India and its main partners. Red and blue indicate the net exporters and net importers of emissions in international trade, respectively. The width of the arrows and the numbers indicate the relative values of emission flows between countries, and the unit is metric tons. (a), (b), (c), and (d) show the results for four selected years: 2000, 2009, 2011, and 2014, respectively. 